\title{
Traditional Knowledge, Sustainability and the Potential Role of Epigenetics
}

\author{
Stuart Walker ${ }^{1 *}$ and Peter Lloyd Jones ${ }^{2}$ \\ ${ }^{1}$ Imagination Lancaster Design Research Centre, Lancaster University, UK \\ ${ }^{2}$ Visiting Design Scientist, Lancaster University, UK
}

*Corresponding author: Stuart Walker, Imagination Lancaster Design Research Centre, Faculty of Arts and Social Sciences, LICA Building, Lancaster University, UK.

To Cite This Article: Stuart Walker and Peter Lloyd Jones, Traditional Knowledge, Sustainability and the Potential Role of Epigenetics. Am J Biomed Sci \& Res. 2019 - 6(3). AJBSR.MS.ID.001028. DOI: 10.34297/AJBSR.2019.06.001028.

Received: November 07, 2019; Published: 眥 November 22, 2019

\section{Introduction}

In our research we have been talking to people who have been part of a traditional, place-based culture and professions for generations. They live in communities around Morecambe Bay, in North West England; the largest expanse of estuarine sands and intertidal mudflats in the U.K. The people we have talked with have considerable knowledge about this unique natural environment, its wildlife, its changing moods and its particularities. Their knowledge encompasses both historical and contemporary issues, including those related to shifting patterns that may well be associated with climate change. Individuals and communities who live and work on Morecambe Bay are also committed to its long-term care and conservation - not least, because their happiness and livelihoods often depend upon it. They have expressed a deep love of the place, which they regard as part of their very identity. They could not contemplate living elsewhere and they feel a strong responsibility to continue contributing to their communities, as well as to their traditional practices and professions, which include fishing, shellfish harvesting, guiding people across rivers and the bay on foot and by ferry, lifeguarding, environmental monitoring and traditional crafts including boat building and repair and, a little to the north, basket making and weaving.

Today, many such customs, crafts and age-old professions are in decline all over the world. There are various reasons for this. It is due partly to urbanization, with new opportunities for young people in the service and digital sectors, which exist beyond their coastal communities [1], Also, many traditional practices, from apprenticeship to master, take years to learn, often involving hard physical labour and frequently they are not very lucrative. Inexpensive produce and goods imported from overseas have also affected these traditions, because often they are more affordable than locally produced alternatives. Products supplied by large corporations are also supported by considerable marketing campaigns, which lie beyond the means of small-scale local enterprises.

These and other factors have served collectively to erode many long-established practices and ways of life. As they disappear, however, in a sense so do we. Recent research that aims to filter population health through the lens of the burgeoning scientific field of epigenetics suggests that health and generational practices within natural environments may in fact be deeply intertwined. This raises an interesting and potentially important question about the loss of these traditions and their relationship to context, including the natural environment, and their critical relationship to sustainable ways of living and doing.

While the majority of research in molecular biology and heredity still largely focuses on how the basic DNA blueprint drives organismal performance and future health prospects, a parallel understanding for how these outcomes may be modified, that lies beyond this predominant dogma, has begun to emerge. This is the field of epigenetics, which encompasses the study of chemical, and potentially heritable modifications that are added to genes other than changes in the basic DNA sequence itself. To coin the words of Conrad Waddington "Genes are not only actors but are also acted upon." [2]. In other words, the physical and chemical microenvironment of cells within tissues represents an epigenetic entity that modifies the genome in a context-dependent fashion. Fast forward to more recent studies, and the notion of "context" in the setting of epigenesis has begun to take on another meaning and includes one that can be speculated to influence certain ways of knowing and doing. A chemical memory of sorts, that is imprinted upon DNA, modifying its behaviour in ways that may be inherited across generations. 
Reported examples of this include trauma-associated traits that can be traced across generations, including within descendants of ex-POWs from the American civil war [3] and individuals whose ancestors survived the holocaust [4]. While the mechanisms that underscore the nature of inherited trauma remain highly contentious, largely due to the relatively small numbers of individuals examined, and/or the sheer complexity of how DNA operates within the whole, a 2014 experimental study in mice revealed trans-generational effects of trauma associated with scent [5]. Collectively, these and other related studies in humans and mice, not only indicate that our experiences may be "recorded" within our cells, but that in some instances, these memories may be inherited in ways that affect our health. These findings also make it reasonable to speculate that other "trauma"-associated scenarios, albeit to lesser degrees, including our removal from natural environments and practices within which we evolved, may also affect our health across generations. Assuming that this is possible, it is also reasonable to imagine that the corollary of these effects, i.e. re-immersion into natural environments and ancient practices, which appear to have positive effects on our well-being at the personal and population health levels - may represent a transgenerational, epiegenetic phenomenon countering the effects of urbanization and industrialization, for example.

\section{Implications}

It may well be the case that understanding epigenetic inheritance will and should become critical to our understanding for designing sustainable futures. Conceivably, if inherited gene modifications are a function of place and of long-standing, often family-based traditional practices that are strongly rooted in context and wedded to the natural environment and its cycles, then, as these traditional communities and practices fall into decline, we may be losing more than we know.

First, there may be critically important traditional knowledge (TK)-associated pathways, including traditional environmental knowledge (TEK) being lost. These are types of knowledge that, today, we are only beginning to understand. It is knowledge held within communities and handed down from one generation to the next [6]. It represents deep knowledge of place that is connected to long-term understandings of human activity and environmental change. However, while it is traditional, it is not static. Over time, holders of traditional knowledge adapt their activities and ethical and moral teachings to fit with prevailing conditions [7]. Traditional knowledge is also holistic; it recognizes the interconnectedness of all aspects of the natural environment [8].

Second, as these traditions disappear, a community's and its individuals' sense of belonging and identity inevitably start to break down and fragment. This phenomenon, known as societal atomization, means that people's ties to place and each other are loosened, even severed, and with it their sense of self in relation to their context - its practices, customs, landscapes, sounds, natural rhythms, climate and light. Potentially, this sense of 'at-homeness' and being part of and within the flow of life is being lost. And, if this is the case, we are losing more that we can tell, more than we can consciously know - for we are losing an intuitive (in-built, inherent) aspect of our very being - a tacitly known but non-explicit facet of who we are.

\section{Conclusions}

While it may not be entirely conclusive that we are subject to trans-generational epigenetic inheritance as it pertains to natural environments and traditional practices undertaken therein, the implications of such a possibility reveal critical areas for future research:

a. Awareness of and sensitivity to context and tradition take on a new significance, because of their connections to people's sense of identity and well-being;

b. Traditional knowledge begins to be seen in a new light, especially when we also recognize that sustainability is deeply dependent on the particularities of place;

c. Areas of knowledge that span human traditions, community, development policy, environmental change, and human genetics and epigenetics reach far beyond any singular discipline;

d. The need for contemporary biology and design to become more attentive to one another's needs.

Hence, interdisciplinary, trans-disciplinary and even postdisciplinary approaches are needed to develop integrated, holistic understandings of these kinds of complex, interdependent systems. This will require cooperative ways of working among scientists, medical researchers, planners, communities, policy makers, experts in traditional practices from crafts and fishing to hunting and agriculture, environmentalists and anthropologists. It will also require the synthetical, integrative expertise and working processes offered by designers, to find ways of bringing together different knowledge areas, lexicons and fields of expertise. Through such means, we can strive to avoid policy and development decisions that not only negatively affect communities but also eradicate those very kinds of place-based knowledge that will be so important for developing sustainable futures. Such collaborative exchange between diverse areas has the potential to generate positive, well-informed outcomes for human benefit in areas ranging from products and processes to services and policies. However, for such exchanges to be effective, better understandings are needed of the cultures and mechanisms within which each operates. We believe a 'lab-studio' model is required. Such a model is in keeping with both scientific and design research. It is a model that allows for dynamic, reciprocal response and change to evolving understandings and situations. It is a model that can also be used as a tool to understand 
past interventions and to inform and critique proposals and future possibilities intended to benefit people. The fundamental premise of such a model is to pose and continually reposition the question as to how science, design and other areas of expertise can and should be more attentive to each other's knowledge, cultures and contributions in order to work together more effectively and collaboratively, while retaining the individual identities of each.

\section{References}

1. Bakewell J, et al. (2019) The Future of Seaside Towns, House of Lords Select Committee on Regenerating Seaside Towns and Communities.

2. Jones PL (2007) Context Messaging: Modeling Biological Form, Princeton Architectural Press. In MODELS by 306090 Books 11: 33-38.

3. Costa D, Yetter N, DeSomer H (2018) Intergenerational transmission of paternal trauma among US Civil War ex-POWs. PNAS 115(4): 1121511220.

4. Kellermann N (2013) Epigenetic transmission of Holocaust trauma: can nightmares be inherited? Isr J Psychiatry Relat Sci 50(1) :33-39.

5. Dias B, Ressler K (2014) Parental olfactory experience influences behavior and neural structure in subsequent generations. Nature Neuroscience 17: 89-96.

6. Park C (2007) A Dictionary of Environment and Conservation, Oxford University Press, Oxford, ebook version [2012] Lancaster University Library, UK.

7. Pierotti R, Wildcat D (2000) Traditional Ecological Knowledge: The Third Alternative (Commentary), Ecological Applications, Ecological Society of America 10(5): 1338-1339.

8. Turner NJ, Boelscher Ignace M, Ignace R (2000) Traditional Ecological Knowledge and Wisdom of Aboriginal Peoples in British Columbia. Ecological Applications 10(5): 1275-1287. 